\title{
Health study sets sights on a million people
}

David Cyranoski and Rachael Williams, Tokyo Epidemiologists are meeting this week to discuss whether they can pull off the biggest health survey ever attempted. The mammoth project would track the genes, lifestyles and health of more than a million people across Asia, giving researchers unprecedented power to pin down subtle causes of disease.

The aim is to understand how environmental factors such as diet, smoking and exercise affect disease development, and how this risk varies with genetic make-up. The Asian study, dreamed up by John Potter of the Fred Hutchinson Cancer Research Center in Seattle, Washington, is intended to span Malaysia, India, Korea, Japan, China, Taiwan and Singapore. It would dwarf most national efforts, which generally include fewer than
100,000 people. And it would be twice as large, and cover a much wider range of lifestyles, than the European Prospective Investigation into Cancer and Nutrition (EPIC), the largest study of diet and health so far.

Potter plans to focus on people over 50 and follow them for as long as possible. As well as asking questions about lifestyle, the study would collect regular blood samples to monitor how biological markers such as proteins and RNAs change in the early stages of disease.

Some forty epidemiologists and other researchers from Asia and elsewhere are meeting in Seattle this week to discuss the project amid great enthusiasm. "A large sample with varied dietary habits offers major advantages," says Nadia Slimani of the
International Agency for Research on Cancer in Lyon, France, a nutritionist who has worked on EPIC. Single-country studies can miss connections, she says. One wide-ranging European study found a clear link between fibre intake and colon cancer, whereas a similar study based in the United States picked up nothing.

Such a large study would also have the statistical power to show up causes of rare and less-studied diseases such as brain or kidney cancer, says Shoichiro Tsugane of the National Cancer Center in Tokyo, Japan. "It would be very powerful," he says.

And it could turn up uniquely Asian insights into disease. For example, known risk factors for breast cancer, such as few children and obesity, do not hold for the oestrogen receptor-negative class of breast tumours, which are particularly common in Asia. "No one knows what causes these," says Potter.

Pulling off such a huge collaboration won't be easy. Tricky issues include privacy and data distribution, as well as how to compare data from different regions. EPIC got round that last problem by giving standard questionnaires to a small proportion of each study population to calibrate the results.

Working across such diverse cultures will pose special challenges. What foods should go on the questionnaire is just one. Kee Sing Chia, a medical epidemiologist at the National University of Singapore, spent four years working out nutrition tables for just 200 dishes for a health survey of Singapore's Chinese population. Extending that to Singapore's Malay and Indian cuisines and then to others across the region will be a "horrendous task", he says. "Instead of being a researcher, I could open a restaurant.”

\section{Gene therapists urged to learn more immunology}

\section{Erika Check, Washington}

How do you resurrect a therapy stalled by a crippling combination of regulatory, financial and scientific hurdles? At a meeting in Arlington, Virginia, last week, gene therapists spelled out the problems in unflinching detail, but concluded that gene therapy can be revived - if its practitioners are willing to make changes.

"This course of events has been experienced by other new therapeutics," said Katherine High, president of the American Society of Gene Therapy, which convened the meeting on 7-8 April. She cited the example of monoclonal antibodies, which went through a cycle of hype, disappointment and eventual medical and commercial success.

Concerns about safety have made patients reluctant to participate in clinical trials, and regulatory requirements have made trials expensive. The National Institutes of Health (NIH) does not have the resources to fund many clinical trials, and big pharmaceutical companies are not interested in diseases that afflict relatively few patients.

So how can gene therapy continue? Suggestions from the meeting included modifying the molecules used to deliver the genes, developing better animal models, and performing more rigorous safety evaluations before beginning trials in people.

But Daniel Salomon, a transplant surgeon at The Scripps Research Institute in La Jolla, California, who headed up the US Food and Drug Administration's advisory panel on gene therapy until 2003, thinks the field needs a more profound change of approach.

He argues that trials ran into safety problems because gene therapists did not take the body's immune response seriously enough. "Everything you do that damages healthy tissue, you're going to pay a price for."

Others agree. "Some of us do molecular biology because we don't have to learn immunology," says Savio Woo, a gene therapist at the Mount Sinai School of Medicine in New York.

Salomon is hopeful nevertheless. Gene therapists must understand and plan for the immune system's response to experimental treatments, he advises. This could entail using immunosuppressive drugs. "Gene therapy is going to happen," he says. "A dose of reality is all I'm talking about." 